\title{
Increase in plant productivity and soil fertility based on monitoring studies in the system of test polygons
}

\author{
Andrey Komarov ${ }^{1, *}$, and Peter Lekomtsev ${ }^{2}$ \\ ${ }^{1}$ Agrophysical Researche Institute (ARI), 195420, 14, Grazhdansky pr., Saint Petersburg, \\ Russian Federation \\ ${ }^{2}$ Russian State Hydrometeorological University (RSHU), 192007, 79, Voronezhskaya st., \\ Saint Petersburg, Russian Federation
}

\begin{abstract}
The work presents the formation of a system for assessing soil fertility and plant development using test monitoring polygons. Monitoring polygons became the basis for the introduction of modern technologies to increase plant productivity and soil fertility. The monitoring sites were located in the main agro-climatic regions of the Leningrad Region on soil types typical for the respective region. Analysis of the dynamics of the main parameters of soil fertility in test plots shows a tendency towards a decrease in the content of mobile forms of potassium and acidification of soils, as well as other signs of degradation. A decrease in soil fertility is associated with a decrease in the proportion of applied fertilizers and a decrease in soil liming. This process develops on all types of soils, with the exception of those areas that are located in suburban farms. The data for the test sites are consistent with the overall results of the agrochemical surveys. For industrial practice, test sites and information collected on them can serve as "information keys" for decoding space and aerial photographs in order to assess the state of agroecosystems, monitor changes in soil fertility and plant development. On the example of the cultivation of spring wheat, the way of precision assessment of the management of the productivity of cultivated crops and the increase of soil fertility is shown. The mechanism for the implementation of the plant productivity management system was carried out with the introduction of elements of precision farming.
\end{abstract}

\section{Introduction}

The reduction of the stations of research institutes and base stations of the VIR, which occurred after the collapse of the USSR, led to a significant decrease in the geographical areas, species and varietal diversity of the studied and cultivated crops, a decrease in the intensification of agriculture and, accordingly, to a decrease in soil fertility. With such a significant loss of quantitative indicators, is it possible to preserve scientific potential, develop breeding and genetic programs and replenish seed resources?

${ }^{*}$ Corresponding author: Zelenydar@mail.ru 
Perhaps one of the ways out of the protracted crisis is to solve problems at a new qualitative level. So, the problem of spatial dissemination of the results of field and genetic selection studies of a scientific institution is so far being solved as follows - a research university is located on the territory of a specific region, which means that this is the sphere of its service. However, there are currently no methods and criteria for transferring research data from the agropoligon to other fields, to other natural conditions. It is long overdue to form a unified hierarchical system for monitoring the productivity of Russian lands, which could provide an increase in the information content of various, but still working "without a bundle" of various services, which can ensure the minimization of costs, the preservation of the intellectual and scientific-production base of the NRU, the effective use of all resources, replenishment of soil fertility.

At present, further theoretical substantiation of the formation of a methodology for the design of new farming systems on a landscape basis is needed, including the introduction of new elements of intensification of production based on precision farming [1,2]. This requires: to develop a system of agroecological zoning of the territory of Russia; to develop new fundamental and applied developments on the formation of farming and crop production systems, to develop a system for monitoring the state of agricultural land, monitoring natural plant resources.

\section{Methods}

Work on monitoring soil fertility of agricultural lands was carried out in the North-West region of the Russian Federation, covering the entire territory of the Leningrad region. The studies were carried out on the basis of methodological recommendations [3,4]. The first stage of research covered the period from 1994 to 2005, where a network of 25 reference sites was deployed. The second stage, from 2008 to 2019, included the formation of 12 test sites covering the main features of landscape, agroclimatic, soil, agricultural production and other conditions of the area and agricultural production. A special testing ground is the main scientific, methodological and experimental demonstration ground (Men'kovskaya station of the Agrophysical Institute), where the main development of a new experimental and physical and technical base for adaptive landscape agriculture is carried out, for subsequent adaptation to the conditions of other test sites in the region. It was at this test site that the third stage was carried out - the development and implementation of control techniques for precision farming [5].

The network of test sites, covering the territory of the Leningrad region, was formed from the calculation of at least 2 in each of the 5 existing agro-climatic regions of the region (Fig. 1). Monitoring polygons, with an area of 20-50 hectares, were selected on soils typical for this territory, in conditions where economic activities are carried out. At the same time, those soils were also assessed that, for one reason or another, were withdrawn from intensive agricultural use. The selection of test sites was carried out in such a way that they served as an information carrier of the most characteristic factors of productivity, technological characteristics of soils and crops for a particular soil and climatic zone. Within each polygon, the main regionalized crops and varieties were cultivated and adapted technologies were implemented. The information collected at the landfills was designed to provide agro-technological solutions not only at the landfill itself, but also on the territory served by the landfill. The scientific and methodological basis for the work was formed on the basis of modern economic policy using a modern scientific and technical base based on the principles of precision farming and methods of geostatistics [6,7]. The work was carried out with the use of mobile information and measuring devices that provide coordinate referencing by GPS receivers, the use of Earth remote sensing data - ERS [5,7-8]. In addition, according to the selected coordinates of the fields in dynamics, the state of the soil 
and vegetation cover was assessed [8-10]. The assessment of vegetation and other NDVI indices was carried out using space and aerial images, where unmanned aerial vehicles (UAVs) with a wing and copters were used [11]. The latter was necessary to create models for optimizing the use of land and plant resources, which provided for the formation of scientific and technical programs for further reforming the land service; conducting an inventory of land resources and creating models for their optimal use; creation of a service that integrates the activities of soil, land management, agrochemical, plant growing and other services on a modern basis. The ongoing monitoring of the fertility of agricultural lands corresponded to the list of indicators and research methods defined by the relevant GOSTs. Precision research was carried out on the basis of the scientific and methodological foundations for managing the production process of cultivated crops in the system of precision farming [5, 12-14]. When introducing a system of precision farming in experimental plots, precision machinery and equipment were used.

\section{Results}

Monitoring studies of the first stage, carried out from 1994 to 2005, revealed certain negative trends in the conditions of the Leningrad region (Fig 1,2). Analysis of data on the content of mobile forms of potassium and phosphorus for the period from 1994 to 2005. showed a downward trend in these indicators (Fig. 1).

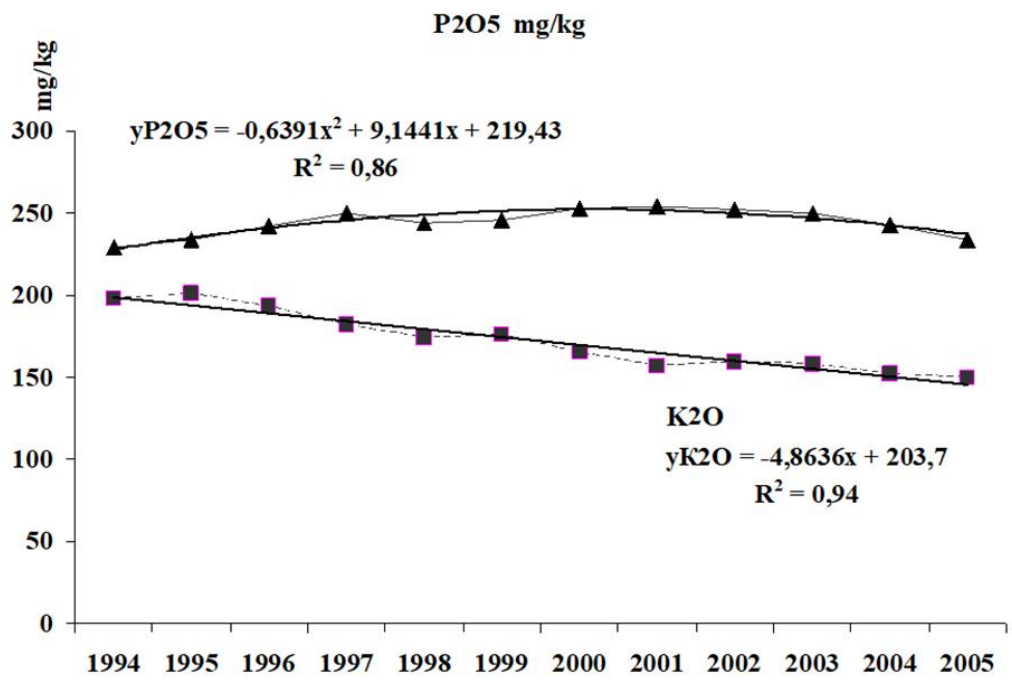

Fig. 1. Dynamics of the content of potassium and phosphorus in the soil by areas of control in the Leningrad region.

At the same time, the trend line for the content of mobile phosphorus in the soil was not described by a linear function. That is, the effect of reducing this indicator is not gradual, but variable. This is probably due to the unevenness of the application of phosphorus fertilizers and the release of soluble phosphates over the years of observation. A satisfactory approximation is applicable only for a polynomial function, where the accuracy of the approximation is $\mathrm{R}^{2}=0.86$. The trend line for potassium content in soil is well described by a simple linear function with a high level of confidence $\left(R^{2}=0.94\right)$. 


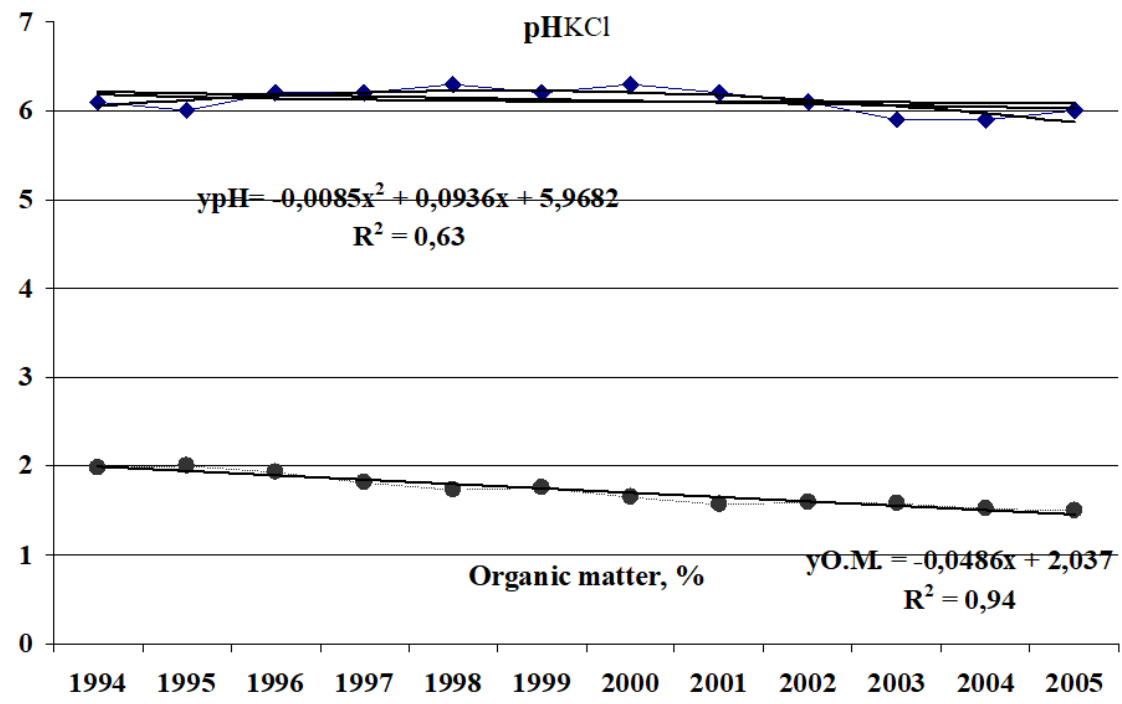

Fig. 2. Change in the content of organic matter in the soil and acidity in the test sites of the Leningrad region.

The change in soil acidity over the years of observation tends to decrease $\mathrm{pH}$ and is not satisfactorily described by either linear or logarithmic functions (Fig. 2). More satisfactory results are obtained by using the polynomial approximation. Although the use of such a trend line for $\mathrm{pH}$ is rather arbitrary and is presented only as an illustration. The most significant indicators of degradation processes in soils reflect a steady decrease in the content of organic matter, where over 10 years the decrease was $0.5-0.6 \%$. The trend towards a decrease in the content of organic matter in the soil is well described by a linear trend line with a high level of accuracy of approximation $(\mathrm{R} 2=0.94)$. The process of reducing soil fertility developed on all types of soils, except for those areas that were located in suburban farms, that is, where a sufficiently high level of fertilization was maintained. It should be noted that the data for the control plots are consistent with the general results of agrochemical studies.

Unfortunately, the monitoring system at reference sites since 2006 lost its existence and, only since 2008, it was reanimated again, albeit on a much smaller scale. First of all, the number of reference polygons decreased from 25 to 10 (2.5 times). Secondly, the newly formed reference polygons began to function practically in new places, therefore, the link to the previously existing ones was very conditional (Fig.3). After all, it is known that the more observation points, the more accurate the result. Nevertheless, during the observation period, it was possible to identify some trends in the direction of changes in soil fertility [910]. Here, the negative phenomena of acidification and a decrease in the content of basic nutrients in soils were already more pronounced [11]. 


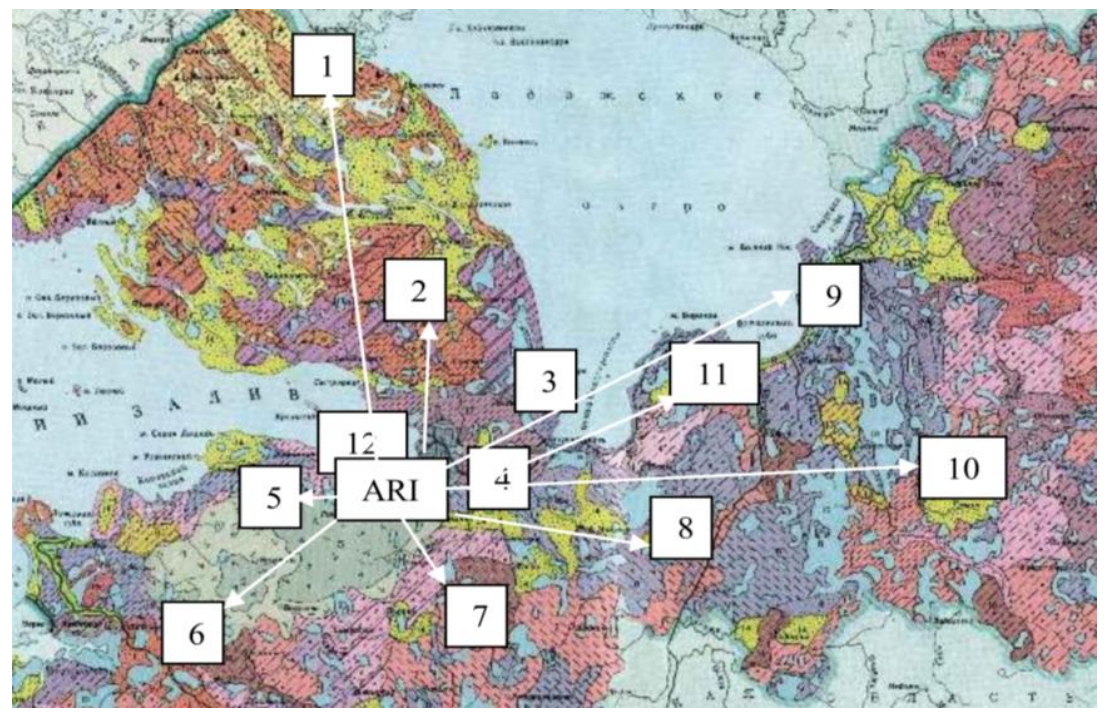

Fig. 3. Layout of monitored monitoring sites on the soil map of the Leningrad Region.

Over the observation period from 2008 to 2019. revealed some stabilization in the content of phosphorus in the soil and a further decrease in the content of potassium and calcium in soils. Especially significant reductions in indicators were observed for exchangeable magnesium, and to a critically low level. Leaching of magnesium from the soil-absorbing complex indicated an increase in degradation processes in some landfills. This process was accompanied by soil acidification.

\section{Discussion}

Based on the study of the effect of intensification of technologies in the system of precision farming (PF), it was shown that the differentiated application of fertilizers increased the yield and quality of cultivated crops. In the PF system, the utilization factor of nutrients increased relative to the generally accepted high-intensity technology with uniform fertilization, which, in turn, ensured greater stability of agricultural landscapes and preservation of soil fertility.

Taking into account that the use of natural resources in agriculture is often accompanied by negative consequences, the necessity of scientific substantiation of the permissible limits of anthropogenic impact on the agricultural landscape, as well as the strategy of rational use of land resources is dictated. In this regard, at the selected test sites, an assessment of changes in soil fertility, the state of agroecosystems was made, a forecast of the development of degradation processes was given; recommendations were developed for the implementation of measures to preserve the fertility of soils and agricultural landscapes, to prevent degradation processes.

A feature of the research at the ARI monitoring site is that due to the coordination of scientific research, the concentration of modern technologies, tools and equipment, the necessary results have been achieved, ensuring the development of a unified methodology. The latter served to form the necessary knowledge and data base, which were later applied at the remaining sites of local monitoring, adapted to the conditions of other regions.

Based on precision fertilization in high-intensity precision farming technology, a decrease in the negative impact of agro-climatic and soil-hydrological factors on the productivity of spring wheat was established. Thus, with precision control of the production 
process in high-intensity precision farming technology, the yield increase reached 0.23 $1.18 \mathrm{t} / \mathrm{ha}^{-1}$, which corresponded to $5.1-76.6 \%$. At the same time, the payback of fertilizers increased by an increase in grain yield. Moreover, a different-quality reaction of the studied varieties to the intensification of technological methods was established: from $27.7 \%$ for the Ester variety to $43.5 \%$ for the Krasnoufimsky-100 variety. Based on the study of the influence of soil factors on the degree of hydromorphism on the distribution of nutrients, it was found that an increase in the degree of gleying in soils leads to a greater localization of nitrogen absorbed by spring wheat plants not in the grain, but in the straw. It is shown that by adjusting the level of intensification of technology (differentiating the system of fertilization), it is possible to increase the degree of nitrogen accumulation in grain. Based on the assessment of the influence of fixed and random factors on the formation of the grain yield of the studied varieties, it was found that the intensification of technologies $(45.8 \%)$ had the maximum effect on the grain yield, the second most important was the influence of weather and climatic conditions (38.9\%) and the minimum , but a significant influence was exerted by the variety-specificity factor $(4.8 \%)$.

Thus, on the basis of the introduction of precision farming technology on the territory of the scientific testing ground of the Agrophysical Institute, results were obtained on the management of the yield of cultivated crops. These data were subsequently disseminated first in the territories of other polygons, and then transferred to the territories of farms located in similar soil and agroclimatic zones.

\section{Conclusions}

Monitoring of soils of agricultural lands on test (reference) polygons (plots) is a system of continuous integrated monitoring of the state of agricultural land, soil fertility, nutrient flows, anthropogenic load, quality and quantity of agricultural products and other parameters. The complex nature of the observations consists in the simultaneous monitoring of the state of agricultural land, the type and intensity of their use, soil fertility, the size and quality of the crop, the amount and quality of precipitation, the quality of ground and waters. This approach ensures timely identification and forecasting of changes in soil fertility, quality and quantity of agricultural products, prevention and elimination of negative processes occurring in the environment during economic activities. When conducting monitoring studies, it is important to identify the share of agriculture in the pollution of water bodies and watercourses, as well as the possibility of calculating the balance and fluxes of nutrients. The outlined tendency towards a decrease in the content of mobile forms of phosphorus and exchangeable potassium in soils, a decrease in the content of organic matter and an increase in soil acidity indicate a decrease in applied fertilizers and soil liming. To restore soil fertility, it is necessary to optimize the application of organic and mineral fertilizers and timely liming the soil. The use of precision research in the precision farming system shows the high efficiency of these technologies, both in terms of increasing yields and maintaining soil fertility.

Based on the studies carried out over the past 10 years, it has been established that no signs of soil erosion and deterioration of the ecological situation both on the territory of the landfills and on the adjacent lands were found during the period of work. Agroecosystems in all types of use (forage, field and vegetable crop rotations) retain a high functional capacity. Agricultural landscapes, including those on reclaimed lands, are stable. No noticeable negative impact of crop production on ground and surface waters was noted. Thus, the system of test polygons can act as a basic basis for assessing the resistance of agrocenoses and the subsequent management of the productivity of cultivated crops and soil fertility. At the same time, the noted tendencies in a decrease in the content of potassium, calcium and, especially, magnesium in soils indicate the beginning of 
degradation processes. This is accompanied by acidification of soils that need liming. When choosing limestone materials, it is necessary to take into account the ratio of calcium and magnesium in their composition. In the best possible degree, it can be dolomite flour. Reducing the use of organic fertilizers can lead to a decrease in the humus content of soils. Thus, during the observation period from 1994 to 2005, there was a slight decrease in the content of organic matter in soils. However, at monitoring sites from 2008 to 2019. no significant decrease in the content of organic matter in soils was found. This indicates some stabilization of this indicator of soil fertility.

When introducing precision farming technology, it is necessary to take into account that different varieties of one type of agricultural crop have different responsiveness to the level of intensification under conditions of soil heterogeneities and give different economic benefits. In production conditions, it is recommended to use high-intensity technologies of precision farming, smoothing (leveling) the background of soil heterogeneity and ensuring an increase in the efficiency of production of the main products of spring wheat. To reduce the cost of grain production, reduce the cost of production and increase profitability, it is advisable to use high-intensity precision farming technology. When introducing new varieties into production, it is necessary to choose varieties with the highest resistance to unfavorable weather and climatic conditions and an increased responsiveness of the yield level to the agrotechnical methods used in technology.

Coordination of soil-agrochemical and selection-genetic works can contribute to a significant expansion of geographical areas, species and varietal diversity of the studied and cultivated crops.

\section{References}

1. E. Panayi, G. W. Peters, G. Kyriakides, PloS ONE, 12, 9 (2017)

2. R. Beluhova-Uzunova, D. Dunchev, Prob.Agr.Econ. Zag. Eko. Rol, 3, 330 (2019)

3. P. A. Sukhanov, V.V. Yakushev, A.V. Konev, D.A. Matveenko, Agroch. Bull., 3 (2011)

4. A. A. Komarov, P.A. Sukhanov, SPbSAU, 21 (2011)

5. P. V. Lekomtsev (Diss. Doct. Biol. s., 2015)

6. Yu. G. Zakharyan, A. A. Komarov, MPRSS, 16, 3 (2019)

7. A. A. Komarov, Yu. G. Zakharyan, B.R. Irmulatov, MPRSS, 18, 3 (2021)

8. P. S. Thenkabail, J. G. Lyon, A. Huete (CRC Press, USA, 2011)

9. A. A. Komarov, YU. G. Zakharyan, A. D. Kirsanov, SPbSAU, 47 (2017)

10. V. M Bure., O.A. Mitrofanova, CES, 10, 4 (2017)

11. S. E. Vitkovskaya, K. F. Shavrina, Agrophys., 1 (2021)

12. Precision agriculture (Gl.FoodSec, 2016)

13. B. Dokin, A. Aletdinova, E3S Web of Conf., 285 (2021)

14. M. Sekandari, I. Masoumi, A. Beiranvand Pour, A. M. Muslim et al., Rem. Sens., 12 (2020) 